DOI: https://doi.org/10.24127/ajpm.v9i3.2539

\title{
PENGEMBANGAN MEDIA ISLAMIC MATH COMICS DALAM MENINGKATKAN PEMAHAMAN MATEMATIS DAN KARAKTER SISWA
}

\author{
Mochamad Abdul Basir ${ }^{1}$, Kurnia Vera Alif Hazira ${ }^{2}$, Imam Kusmaryono ${ }^{3}$ \\ ${ }^{1,2,3}$ Universitas Islam Sultan Agung Semarang, Semarang, Indonesia \\ E-mail: $\quad$ abdulbasir@unissula.ac.id ${ }^{1)}$ \\ kurniavera.ahz99@gmail.com ${ }^{2)}$ \\ kusmaryono@unissula.ac.id $^{3)}$
}

Received 09 December 2019; Received in revised form 14 September 2020; Accepted 23 September 2020

\begin{abstract}
Abstrak
Penelitian ini bertujuan untuk mengetahui tingkat kelayakan media Islamic Math Comics materi perbandingan SMP. Penelitian ini berbentuk penelitian pengembangan R\&D (research \& development) menggunakan metode ADDIE (analyze, design, develop, implement, and evaluate). Dalam penelitian ini hanya dibatasi sampai tahap design saja. Media ini dikembangkan dengan mendesain gambar manual, scan, dan adobe photoshop. Islamic Math Comics merupakan komik matematika materi perbandingan bernuansa islami mengandung bimbingan karakter dan meningkatkan pemahaman matematis siswa. Setelah dihasilkan produk awal akan dilakukan validasi dari ahli materi, ahli media, dan guru matematika. Analisis data menggunakan deskriptif kualitatif. Hasil penelitian ini dari aspek materi diperoleh skor 3,19 "Sangat Layak", aspek bahasa diperoleh skor 3,33 "Sangat Layak", dan aspek penyajian diperoleh skor 3,30 "Sangat Layak". Jadi media ini berada dalam kategori "Sangat Layak" digunakan dan tidak terlepas dari saran atau masukan validator seperti mengembangkan isinya agar lebih sinkron, menambahkan soal tantangan, dan mencantumkan KD/KI secara tertulis.
\end{abstract}

Kata kunci: Bimbingan karakter; islamic math comics; pemahaman matematis.

\begin{abstract}
This study aims to determine the level of feasibility of Islamic Math Comics media for comparison SMP material. This research is in the form of $R \& D$ development research (research \& development) using the ADDIE method (analyze, design, develop, implement, and evaluate). In this study only limited to the design stage. This media was developed by designing manual images, scans, and Adobe Photoshop. Islamic Math Comics is an Islamic comic comparison material containing Islamic character guidance and improving students' mathematical understanding. After the initial product is produced, validation will be carried out from the material experts, media experts, and mathematics teachers. Data analysis using descriptive qualitative. The results of this study from the material aspects obtained a score of 3.19 "Very Feasible", the aspect of language obtained a score of 3.33 "Very Feasible", and the aspect of presentation obtained a score of 3.30 "Very Feasible". So this media is in the category of "Very Eligible" to be used and is inseparable from validator suggestions or input such as developing its contents to be more synchronous, adding challenge questions, and including KD / KI in writing.
\end{abstract}

Keywords : Character guidance; islamic math comics; mathematical understanding.

This is an open access article under the Creative Commons Attribution 4.0 International License

\section{PENDAHULUAN}

Perkembangan pembelajaran dalam dunia pendidikan semakin hari semakin pesat mengikuti perkembangan informasi dan teknologi yang pesat pula. Berbagai macam inovasi, metode, pembelajaran, dan media pembelajaran bermunculan dengan kreasi-kreasi baru untuk mewujudkan agar pendidikan di Indonesia semakin maju guna meningkatkan SDM di Indonesia. Dalam ranah dunia pendidikan 
khususnya matematika sangat diperlukan adanya perkembangan dalam sistem pembelajarannya, apalagi matematika sudah dituding menjadi pelajaran yang ditakuti, rumit, dan susah (Dini, Ngatman, \& Triyono, 2017). Seorang pengajar perlu menginovasi sistem pembelajaran matematika supaya dapat mengubah pola pikir buruk mengenai matematika (Kuncara \& Sujadi, 2016). Sistem pembelajaran inovatif meliputi siswa mampu mengembangkan pemahaman mereka melalui dorongan dari pengajar, pengajar dapat menciptakan alat bantu untuk mempermudah belajar siswa, dan mendorong siswa agar menemukan caranya sendiri dalam menyelesaikan masalah (Purwadhi, 2019). Media pembelajaran dibagi menjadi empat diantaranya media dengan teknologi cetak (buku atau materi visual statis), audio-visual, berbasis komputer, dan gabungan (menggambungkan beberapa macam media dengan dikendalikan oleh komputer) (Purwono, 2014).

Kemampuan pemahaman konsep matematis adalah hal yang sangat penting dalam proses pembelajaran matematika karena sebagai bentuk kemampuan siswa dalam memahami materi dari pengetahuan menjadi bentuk lain yang mudah dimengerti dalam pengaplikasiannya (Karubaba, Rahman, \& Arifin, 2019). Telah dilakukan beberepa penelitian dalam mengembangkan media pembelajaran diantaranya \{Pengembangan Media Komik Pembelajaran Matematika Meningkatkan Motivasi dan Prestasi Belajar Kelas V (Indaryati, 2015), Pengembangan Media Komik Pembelajaran Matematika untuk Meningkatkan Pemahaman Bentuk Soal Cerita Bab Pecahan pada Siswa Kelas V SDN Ngembung (Novianti, 2010),
Pengembangan Media Komik dengan Metode Picture and Picture untuk Meningkatkan Keterampilan iterasi Matematika Kelas IV (Rakasiwi, 2019), Pengembangan Media Pembelajaran Komik Matematika Berbasis Problem Based Learning dengan Manga Studio V05 dan Geogebra (Syukri, Winarni, \& Hidayat, 2018), Eksplorasi Pemahaman Siswa pada Materi Perbandingan Senilai Menggunakan Konteks Cerita di SMP (Hamidah, Putri, \& Somakim, 2018)\} namun hal ini belum ditemukan penelitian terkait pengembangan media pembelajaran visual berbasis Islamic Math Comics yang mencakup pemahaman matematis pada materi matematika perbandingan untuk siswa SMP. Pembelajaran tersebut selain mencakup pemahaman matematis didalamnya juga mengandung bimbingan karakter (jujur, kerja keras, mandiri, peduli sosial, rasa ingin tahu, religius, dan tanggung jawab) (Yuliharti, 2018). Tujuannya agar dapat memaknai hikmah yang didapatkan melalui belajar matematika (matematika kehidupan). Siswa harus didorong untuk berpikir pada tingkat lanjut yang kedepannya dapat mengkontruksi dan membuat sendiri pemahaman mengenai definisi gambaran matematika (Kusmaryono \& Dwijanto, 2016). Belajar matematika tidak cukup hanya pada tingkat pemahaman konsep matematis saja, tetapi diperlukan pendidikan karakter agar ilmu matematika yang dipelajari dapat diterapkan dilingkungannya dengan cara yang baik (Maulani, 2018).

Pengembangan

media pembelajaran visual pada penelitian ini berupa komik sebagai upaya meningkatkan pemahaman matematis siswa. Alasannya karena terdapat beberapa masalah pada siswa diantaranya kurangnya kemampuan 
pemahaman matematis siswa, pembelajaran masih terpaku dengan buku pemerintah saja yang didalamnya kurang fleksibel (salah satunya tulisan soal cerita perbandingan yang membuat siswa mudah bosan, malas membaca, dan berakibat tidak memahami apa soal tersebut), guru dan siswa membutuhkan media pembelajaran, dan siswa membutuhkan pendidikan karakter berbasis islami. Komik tersebut berupa Islamic Math Comics yang menekankan pada pendidikan karakter dan mengulas materi perbandingan. Materi tersebut mencakup kriteria indikator pemahaman matematis diantaranya menyajikan bentuk konsep menjadi representasi matematis, relasional, dan mengaplikasikan (model, diagram, tabel, dan simbol-simbol) untuk mempresentasikan konsep (Hendriana, Rohaeti, \& Sumarmo, 2017). Pengembangan tidak hanya ditekankan pada pemahaman konsep matematis saja, tetapi perlu keseimbangan dengan pendidikan karakter bagi siswa. Tujuan penelitian ini yaitu untuk mengetahui tingkat kelayakan media pembelajaran visual berbasis Islamic Math Comics dalam meningkatkan pemahaman matematis dan karakter siswa materi perbandingan tingkat SMP.

\section{METODE PENELITIAN}

Pada artikel pengembangan media pembelajaran visual berbasis Islamic Math Comics untuk meningkatkan pemahaman matematis dan bimbingan karakter siswa SMP materi perbandingan ini menggunakan jenis penelitian R\&D (Research \& Development) dengan prosedur metode pengembangan ADDIE (analyze, design, develop, implement, and evaluate). R\&D (Research and Development) merupakan suatu penelitian yang dilakukan untuk menghasilkan produk-produk tertentu dan menguji keefektifan produk yang dihasilkan tersebut.

Dalam penelitian ini dibatasi sampai tahap design (desain) saja.Subjek penelitian adalah siswa SMP kelas VII sebanyak 20 siswa. Pengumpulan data berupa lembar validasi dari ahli materi, ahli media, dan guru matematika.

Penelitian ini menggunakan dua teknik analisis data yaitu kuantitatif dan deskriptif kualitatif. Data kuantitatif merupakan suatu data yang dinyatakan dalam bentuk angka, atau data kualitatif yang diangkakan (misal skor: sangat baik $=4$, baik $=3$, kurang baik $=2$, tidak baik = 1). Teknik pengumpulan data menggunakan angket berupa pertanyaan tertutup, dimana angket ini akan ditujukan kepada ahli materi, ahli media, dan guru matematika. Untuk penilaian pemahaman matematis menggunakan soal pre-test dan post-test siswa materi perbandingan, dan untuk penilaian pendidikan karakter menggunakan angket motivasi. Namun dalam penelitian ini hanya dibatasi untuk mengetahui tingkat valid media Islamic Math Comics saja.

Dalam penelitian ini rumus yang digunakan dalam menentukan jarak interval dari tidak layak (TL) sampai sangat layak (SL) adalah:

$$
\bar{x}=\frac{\sum x}{n}
$$

(Safitri, 2019)

Dimana $x$ adalah jumlah skor yang didapat, sedangkan $n$ adalah jumlah data/pertanyaan dalam lembar validasi.

Tabel 1. Interval kevalidan.

\begin{tabular}{cc}
\hline Rata-rata $\overline{(\boldsymbol{x})}$ & Klasifikasi \\
\hline $\mathbf{3 , 0 0} \leq \overline{\boldsymbol{x}}<\mathbf{4 , 0 0}$ & Sangat Layak (SL) \\
$\mathbf{2 , 0 0} \leq \overline{\boldsymbol{x}}<\mathbf{3 , 0 0}$ & Layak (L) \\
$\mathbf{1 , 0 0} \leq \overline{\boldsymbol{x}}<\mathbf{2 , 0 0}$ & Kurang Layak (KL) \\
$\mathbf{0 , 0 0} \leq \overline{\boldsymbol{x}}<\mathbf{1 , 0 0}$ & Tidak Layak (TL) \\
\hline
\end{tabular}


DOI: https://doi.org/10.24127/ajpm.v9i3.2539

Berdasarkan jarak interval tersebut, disusun tabel untuk menentukan tingkat kriteria analisis data (Sugiyono, 2017) yang dihasilkan seperti yang tertera pada Tabel 1.

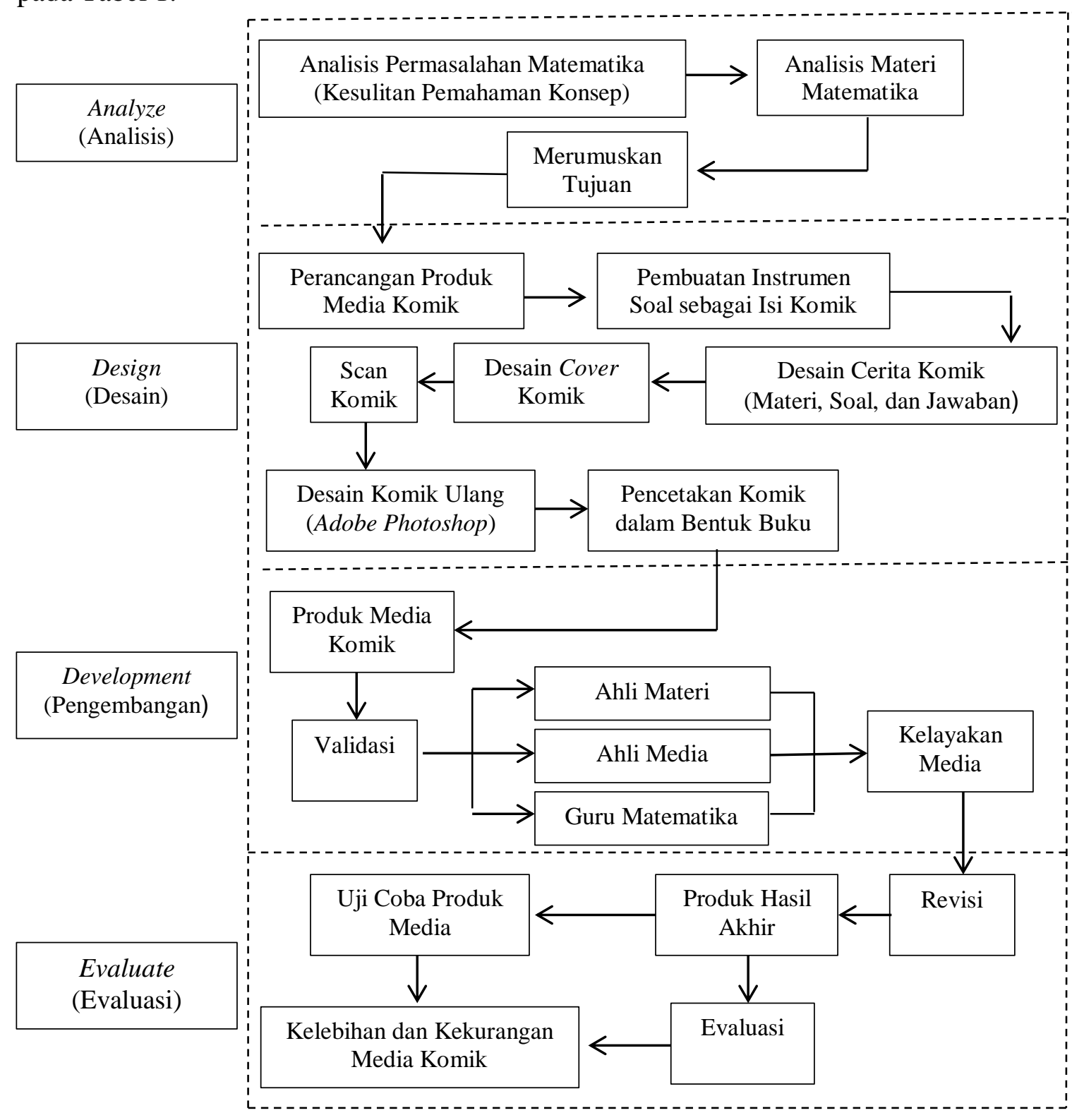

Secara keseluruhan, tahapantahapan pengembangan yang dilakukan dapat dilihat pada Gambar 1.

Gambar 1. Tahapan-tahapan pengembangan media Islamic Math Comics.

HASIL DAN PEMBAHASAN

Hasil penelitian dan pengembangan ini yaitu media pembelajaran visual berbasis Islamic Math Comics materi perbandingan. Penelitian ini menggunakan jenis 
desain), development (pengembangan), dan evaluate (evaluasi), namun didalam penelitian ini membatasi sampai pada tahap design (desain) saja. Sampel gambar dari media pembelajaran visual berbasis Islamic Math Comics materi perbandingan dapat dilihat pada gambar 2, 3, dan 4, yang masing-masing adalah cover dan contoh isi dalam media pembelajaran visual berbasis Islamic Math Comics materi perbandingan.

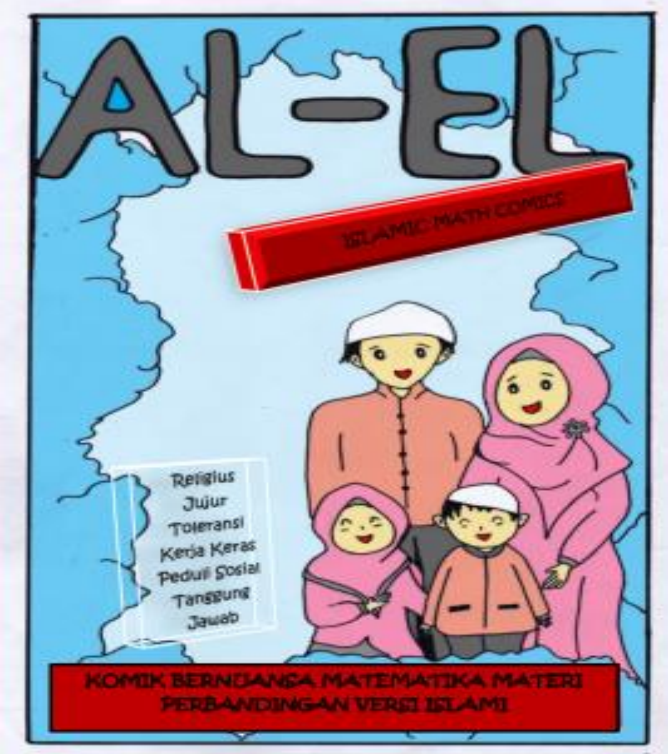

Gambar 2. Cover Islamic Math Comics.

Cover Islamic Math Comics memberikan gambaran kepada pembaca bahwa dalam komik ini membahas matematika materi perbandingan yang bernuansa islami dan mengandung pendidikan karakter (jujur, kerja keras, peduli sosial, religius, tanggung jawab, dan toleransi), dan menggambarkan tokoh yang berperan dalam komik tersebut adalah anak laki-laki bernama $\mathrm{Al}$ dan anak perempuan bernama El. Cover komik tersebut menunjukkan hubungan harmonis sebuah keluarga (parenting).

Pada Gambar 3 menunjukkan bahwa Islamic Math Comics ini didesain agar dapat meningkatkan pemahaman konsep matematis siswa.
Materi dalam komik ini diambil dari beberapa soal cerita perbandingan kemudian didesain menjadi sebuah percakapan komik yang menyenangkan, hal ini membantu siswa untuk mempermudah imajinasi siwa dalam menerapkan konsep perbandingan.

Pada Gambar 4 menunjukkan bahwa Islamic Math Comics ini didesain agar dapat memberikan bimbingan karakter pada siswa. Misalnya pada contoh komik tersebut menceritakan bahwa bapak Kusna menjelaskan kepada anaknya Ali tentang hikmah belajar perbandingan atau rasio "dalam perbandingan mengajarkan kita untuk bersikap adil dan sederhana, memang keadilan yang paling adil adalah milik Allah SWT namun kita sebagai manusia juga harus berusaha untuk adil dan sederhana, sesungguhnya Allah tidak menyukai hal yang berlebihan". Bimbingan karakter yang didapat dari penggalan cerita komik ini adalah mengacu pada aspek religius, adil, dan toleransi.
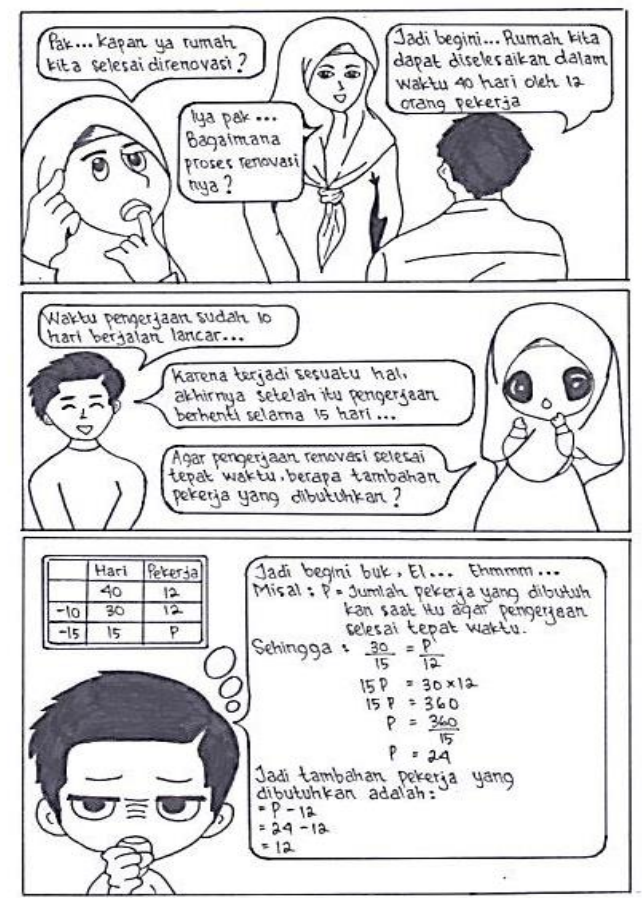

Gambar 3. Contoh isi Islamic Math Comics. 


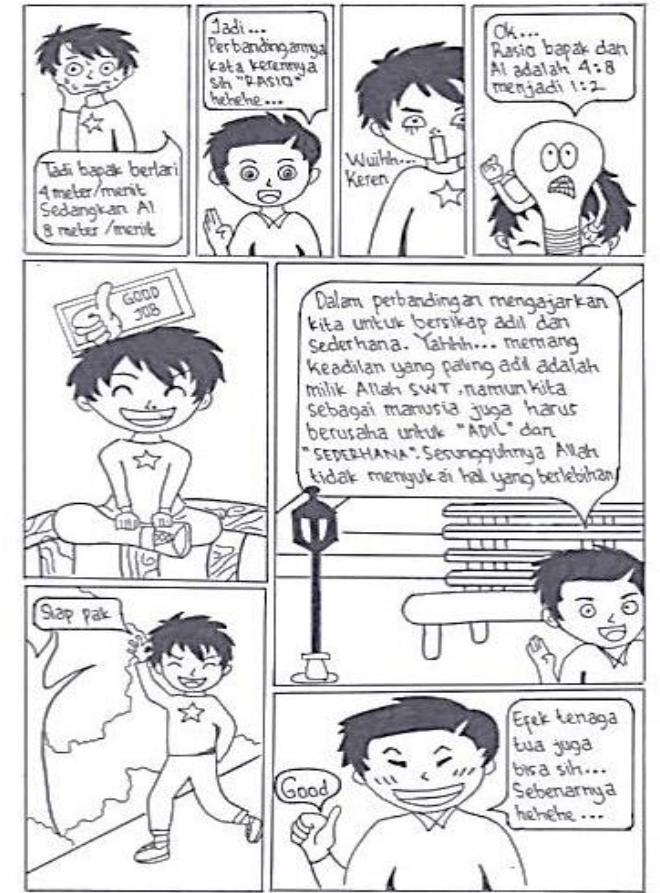

Gambar 4. Contoh isi Islamic Math Comics.

Hasil pengujian terhadap kelayakan media pembelajaran visual berbasis Islamic Math Comics materi perbandingan dapat dilihat pada Tabel 2. Data yang disajikan meliputi rata-rata untuk masing-masing aspek, rata-rata keseluruhan dan kesimpulan dari kriteria yang dipenuhi.

Berdasarkan Tabel 2 hasil penelitian kelayakan Islamic Math
Comics bahwa pada aspek materi diperoleh rata-rata 3,19 artinya media mempunyai tingkat kriteria sangat layak, hal ini ditinjau dari kesesuaian materi (SK dan KD), kebenaran konsep, tingkat keakuratan materi, penyampaian materi secara sistematis, dan meningkatkan kompetensi siswa. Pada aspek bahasa diperoleh rata-rata 3,33 artinya media memiliki tingkat kriteria sangat layak ditinjau dari tingkatan bahasa yang digunakan, penggunaan peristilahan yang tepat, dan kesesuaian bahasa. Pada aspek penyajian diperoleh rata-rata 3,30 artinya media memiliki kriteria sangat layak ditinjau dari penyajian materi logis dan sistematis, melibatkan siswa secara aktif, dan mempertimbangkan kebermanfaatan dan kebermaknaan. Dari rincian ratarata validasi tiap aspek maka total yang diperoleh 9,82 dengan rata-rata hasil akhir 3,27. Jadi media pembelajaran visual berbasis Islamic Math Comics materi perbandingan ini dapat disimpulkan memiliki kriteria sangat layak untuk digunakan. Akan tetapi, kriteria hasil ini tidak bisa terlepas dari masukan atau saran yang disampaikan oleh validator.

Tabel 2. Hasil validasi media Islamic Math Comics

\begin{tabular}{lccccc}
\hline & \multicolumn{2}{c}{ Rata-Rata Validasi } & $\begin{array}{c}\text { Rata-Rata } \\
\text { Keseluruhan }\end{array}$ & Kriteria \\
\hline Aspek Materi & 3,05 & 3,55 & 2,96 & 3,19 & Sangat Layak \\
Aspek Bahasa & 3,11 & 3,67 & 3,22 & 3,33 & Sangat Layak \\
Aspek Penyajian & 3,09 & 3,64 & 3,18 & 3,30 & Sangat Layak \\
\hline Total & & & & 9,82 & \\
\hline Hasil Akhir & & & 3,27 & Sangat Layak \\
\hline
\end{tabular}

Dari rincian Tabel 2 terdapat beberapa hal mengenai media Islamic Math Comics yang perlu dikembangkan lagi. Menurut ahli media komik ini dapat digunakan untuk tahap lanjut penelitian tindakan kelas (uji coba kelas) dan terlepas dari itu perlu adanya tambahan berupa daftar isi, lebih 
menonjolkan cover sehingga pembaca akan langsung paham tentang gambaran isi dari komik tersebut yang menunjukkan materi matematika perbandingan bernuansa islami dan bimbingan karakter, membenahi beberapa cerita yang missing, menambahkan profil atau tokoh matematikawan dihalaman awal, dan jika ingin dikembangkan lebih dalam dan bisa dipublikasikan maka sesuaikan dengan kriteria halaman komik menurut sistem ISBN. Menurut ahli materi komik ini dapat digunakan dan memenuhi kriteria dalam meningkatkan pemahaman matematis siswa melalui penelitian tindakan kelas namun perlu adanya tambahan standar kompetensi (KI/KD) yang dipaparkan secara tertulis dihalaman awal komik, dikombinasikan dengan gambar yang berwarna meskipun tidak semua halaman yang diwarnai, ada penjelasan diawal tentang isi komik seperti dibagi tiap chapter, menambahkan soal tantangan atau kuis, membenahi beberapa cerita yang missing, dan menyinkronkan gambar tokoh. Menurut guru matematika komik ini sudah dapat digunakan dalam tahap lanjut dalam penelitian tindakan kelas, media komik ini menarik terutama untuk usia SMP sehingga bisa menambah motivasi siswa dalam mempelajari matematika khususnya materi perbandingan, namun perlu ada beberapa dalam penggunaan tanda baca dalam percakapan komik yang diperhatikan, dan kedepannya komik ini dapat dikembangkan untuk materimateri yang lain.

Berdasarkan paparan diatas disimpulkan secara keseluruhan bahwa media pembelajaran visual berbasis Islamic Math Comics materi perbandingan memiliki kriteria sangat layak untuk digunakan, dan dapat digunakan untuk tahap lanjut dalam penelitian tindakan kelas (uji coba kelas) kedepannya, serta tidak terlepas dari saran atau masukan validator diantanya mencantumkan daftar isi, mengembangkan cover dari Islamic Math Comics agar dapat lebih menonjolkan ilustrasi matematika materi perbandingan, membenahi beberapa cerita yang missing, memberikan tambahan soal tantangan, mencantumkan standar kompetensi (KD/KI) dalam bentuk tulisan dihalaman awal, menyeimbangkan karakter tokoh, menambahkan profil atau tokoh matematikawan sebagai motivasi pada halaman awal, dan memperhatikan tanda baca yang ditulis. Dari hasil yang disimpulkan maka media Islamic Math Comics ini dapat dilanjutkan menuju tahap penelitian penerapan uji coba lapangan untuk melihat efektifitas dari media aygn dihasilkan.

Penelitian ini sejalan dengan penelitian dari Indaryati (2005) yang berjudul Pengembangan Media Komik Pembelajaran Matematika Meningkatkan Motivasi dan Prestasi Belajar Kelas V, dan penelitian dari Syukri (2018) yang berjudul Pengembangan Media Pembelajaran Komik Matematika Berbasis Problem Based Learning dengan Manga Studio V05 dan Geogebra. Berdasarkan state of the art dari kedua penelitian tersebut, pada penelitian ini mengembangkan penelitian yang sama menggunakan media komik, namun berbeda. Perbedaannya adalah pada penelitian ini menambahkan media komik berbasis pendidikan karakter islami, dan komik ini dibuat handmade (tulisan tangan) yang proses pewarnaannya menggunakan Adobe Photoshop tanpa merubah ciri khas dari Islamic Math Comics ini. Alasannya adalah untuk memotivasi siswa selain dibidang 
matematika itu sendiri juga mengajak siswa untuk berani berkarya dengan kemampuan yang dimilikinya serta penambahan pendidikan karakter yang sangat penting untuk kehidupan.

\section{KESIMPULAN DAN SARAN}

Berdasarkan hasil penelitian mengenai pengembangan media Islamic Math Comics dalam meningkatkan pemahaman matematis dan karakter siswa bahwa media pembelajaran visual berbasis Islamic Math Comics dalam meningkatkan pemahaman matematis dan karakter siswa berada dalam kategori "Sangat Layak" dan dapat digunakan maupun dikembangkan lagi dalam pembelajaran matematika terutama materi perbandingan.

Berdasarkan kesimpulan dalam penelitian pengembangan ini dari beberapa saran dan masukan yang telah diberikan dapat dijadikan acuan bagi penelitian selanjutnya. Peneliti diharapkan dapat mengembangkan media pembelajaran visual berbasis Islamic Math Comics menjadi lebih baik lagi dan dapat disebarluaskan sebagai alternatif pembelajaran matematika terutama pada materi perbandingan.

\section{DAFTAR PUSTAKA}

Dini, I., Ngatman, \& Triyono. (2017). Penerapan Pendekatan Realistic Mathematics Education (Rme) Dengan Media Blok Pecahan Dalam Peningkatan Hasil Belajar Matematika Tentang Pecahan Pada Siswa Kelas IV SD. Kalam Cendikia, 5(4.1), 310-313.

Hamidah, D., Putri, R. I. I., \& Somakim, S. (2018). Eksplorasi Pemahaman Siswa pada Materi Perbandingan Senilai Menggunakan Konteks Cerita di SMP. Jurnal Riset Pendidikan dan
Inovasi Pembelajaran Matematika (JRPIPM),1(1),1.https://doi.org/10. 26740/jrpipm.v1n1.p1-10

Hendriana, H., Rohaeti, E. E., \& Sumarmo, U. (2017). Hard Skills dan Soft Skills Matematik Siswa. Bandung: PT.Refika Aditama.

Indaryati, J. (2015). Pengembangan Media Komik Pembelajaran Matematika Meningkatkan Motivasi dan Prestasi Belajar Kelas V. Yogyakarta: Jurnal Prima Edukasia, 3(1), 84-96. https://doi.org/10.21831/jpe.v3i1.4 067.

Karubaba, S. A. M., Rahman, B., \& Arifin. (2019). Pengaruh Model Pembelajaran Kooperatif Tipe Think Pair Square Terhadap Kemampuan Pemahaman Konsep Matematis Siswa. Indomath Indonesia Mathematics Educations, 2(1), 37-44. http://dx.doi.org/10.30738/indomat h.v2i1.3150.

Kuncara, A. W., \& Sujadi, I. (2016). Analisis Proses Pembelajaran Matematika Berdasarkan Kurikulum 2013 pada Materi Pokok Peluang Kelas X SMA Negeri 1 Surakarta. Jurnal Elektronik Pembelajaran Matematika, 4(3), 352-365.

Kusmaryono, I., \& Dwijanto, D. (2016). Peranan Representasi Dan Disposisi Matematis Siswa Terhadap Peningkatan Mathematical Power. JIPMat, 1(1), 19-28. https://doi.org/10.26877/jip mat.v1i1.1089 
DOI: https://doi.org/10.24127/ajpm.v9i3.2539

Maulani, F. (2018). Keefektifan Islamic Make A Match Based Learning Terhadap Pemahaman Konsep Siswa Materi Segi Empat. KONTINU: Jurnal Pendidikan Didaktik Matematika, 1(2), 1-10. http://dx.doi.org/10.30659/kontinu. 1.2.\%25p.

Novianti, R. D. (2010). Pengembangan Media Komik Pembelajaran Matematika untuk Meningkatkan Pemahaman Bentuk Soal Cerita Bab Pecahan Pada Siswa Kelas V SDN Ngembung. Surabaya: Jurnal Mahasiswa Teknologi Pendidikan, 1(1),79-90.

Purwadhi. (2019). Pembelajaran Inovatif dalam Pembentukan Karakter Siswa. MIMBAR PENDIDIKAN: Jurnal Indonesia Untuk Kajian Pendidikan, 4(1), 2134.

Purwono, J. (2014). Penggunaan Media Audio-Visual pada Mata Pelajaran Ilmu Pengetahuan Alam di Sekolah Menengah Pertama egeri 1 Pacitan. Surakarta: Jurnal Teknologi Pendidikan Dan Pembelajaran, 2(2), 127-144.

Rakasiwi, N. (2019). Pengembangan Media Komik dengan Metode Picture and Picture untuk Meningkatkan Keterampilan Literasi Matematika Kelas IV. Semarang: AKSIOMA: Jurnal Matematika Dan Pendidikan Matematika, 10(1), 60-70. https://doi.org/10.26877/aks.v10i1. 3741.
Safitri, I. A. (2019). Skripsi Pengembangan Majalah Elektronik Berbasis Literasi Matematika untuk Siswa SMP Kelas VII. https://doi.org/10.1017 /CBO9781107415324.004

Sugiyono. (2017). Metode Penelitian Kuantitatif, Kualitatif, dan $R \& D$ (26th ed.). Bandung: ALFABETA.

Syukri, R., Winarni, S., \& Hidayat, R. (2018). Pengembangan Media Pembelajaran Komik Matematika Berbasis Problem Based Learning dengan Manga Studio V05 dan Geogebra. Jambi: Geogebra. Jambi: EDUMATICA Jurnal Pendidikan Matematika, 8(2), 8191. doi:10.22437/edumatica.v8i2.5486

Yuliharti. (2018). Pembentukan Karakter Islam dalam Hadis. POTENSIA: Jurnal Kependidikan Islam, 4(2), 216-228. 